\title{
Copper Cu 64-CB-TE1A1P-PEG4-LLP2A
}

National Cancer Institute

\section{Source}

National Cancer Institute. Copper CU 64-CB-TE1A1P-PEG4-LLP2A. NCI Thesaurus. Code C156772.

A radioconjug ate containing LLP2A, a high-affinity peptidomimetic lig and for the tumorassociated antigen (TAA) very-late-antigen-4 (VLA-4; VLA 4; alpha4beta1 integ rin; CD49d/CD29), conjug ated, via the chelator 1,4,8,11-tetraazacyclotetradecane-1(methane phosphonic acid)-8-(methane carboxylic acid) (CB-TE1A1P), to the radioisotope copper Cu 64, and conjug ated to polyethylene glycol (PEG) chains that can potentially be used as a diagnostic imaging agent of VLA-4-expressing tumor cells using positronemitting tomog raphy (PET). Upon administration, copper Cu 64-CB-TE1A1P-PEG4LLP2A targets, binds to and is taken up by VLA-4-expressing tumor cells. Upon PET, the VLA-4-expressing tumor cells can be visualized, and the tumor can be assessed. VLA-4, a transmembrane adhesion receptor overexpressed and activated on various tumor cell types and surrounding stroma, plays an important role in tumor growth, angiogenesis, metastasis, drug resistance and immune responses. Pegylation optimizes the pharmacokinetic profile of 64CU-LLP2A. 